\title{
Antibacterial effects of conventional glass ionomer cement
}

\author{
Dimkov $\mathrm{A}^{1}$, Gjorgievska $\mathrm{E}^{1}$, Nicholson $\mathrm{JW}^{2}$, Kaftandzieva $\mathrm{A}^{3}$ \\ Department of Paediatric and Preventive Dentistry, Faculty of Dental Medicine, University \\ “Ss Cyril and Methodius”, Skopje, Macedonia. dimkovaleksandar@gmail.com
}

\begin{abstract}
OBJECTIVES: The antibacterial activity of conventional glass ionomer cement against three different microorganism strains alone and following incorporation of 1, 2 and $3 \%$ Benzalkonium Chloride and Cetylpyridinium Chloride was evaluated.

METHODS: Agar diffusion method was used to determine the inhibitory effect of the conventional glass ionomer cement ChemFlex on Streptococcus mutans, Lactobacillus casei and Actinomyces viscosus. Bacterial strains were inoculated into $\mathrm{BHIB}$, and incubated in an anaerobic atmosphere $\left(37^{\circ} \mathrm{C}\right)$. From the bacteria grown in the liquid medium, the density of the inoculum was set to be equivalent to McFarland 2 standard. In Shaedler agar, $350 \mu \mathrm{L}$ of the bacterial suspension were equally spread. Specimens $(4 \mathrm{~mm} \times 6 \mathrm{~mm})$ were prepared from the cement without and with addition of 1,2 and $3 \%$ Benzalkonium Chloride and Cetylpyridinium Chloride. The inhibition zones were determined after 48 hours, after 2, 7 and 21 days of incubation.

RESULTS: The combination ChemFlex + Benzalkonium Chloride has the best effect on the three analysed bacteria. The Benzalkonium Chloride antibacterial compound has a stronger antibacterial effect than Cetylpyridinium Chloride. CONCLUSIONS: Glass ionomer cements can potentially be used as a medium for slow release of active antimicrobial components, and they have the potential to improve clinical outcomes of the cements (Tab. 3, Fig. 3, Ref. 31). Text in PDF www.elis.sk.

KEY WORDS: antimicrobial agents, benzalkonium chloride, cetylpyridinium chloride, glass ionomer cement, cariogenic microorganisms.
\end{abstract}

\section{Introduction}

The common point in all contemporary theories regarding caries development is that dental caries is an infectious disease, resulting in destruction of the tooth structure, caused by microorganisms, Streptococcus mutans above all $(1,2)$. The most common isolated microorganisms in the mouth of a newborn are Streptococcus salivarius, Staphylococcus epidermidis, Neisseria species and Veillonella species. After the teeth eruption and the development of gingival margins, where the concentration of oxygen is less than

${ }^{1}$ Department of Paediatric and Preventive Dentistry, Faculty of Dental Medicine, University “Ss Cyril and Methodius", Skopje, Macedonia, ${ }^{2} \mathrm{St}$ Mary's University College, Twickenham, London, UK, and ${ }^{3}$ Department of Microbiology and Parasitology, Faculty of Medicine, University "Ss Cyril and Methodius" Skopje, Republic of Macedonia

Address for correspondence: Dr. A. Dimkov, DDS, PhD, Faculty of Dental Medicine, Department of Paediatric and Preventive Dentistry, Vodnjanska 17, 1000 Skopje, Macedonia

Phone: +38923118553

Acknowledgements: The research presented in this paper is a part of a wider range research done in the scope of my $\mathrm{PhD}$ thesis performed at the School of Science, University of Greenwich, UK and at the Faculty of Dentistry - Skopje, R.Macedonia. I would like to thank Professor John W. Nicholson for the award of a Visiting Fellowship which allowed me to do experiments with the mechanical and chemical properties of glassionomer cements. I would also like to thank Professor Nikola Panovski whose support allowed the complete experimental work reported in this paper to be carried out in Institute for Microbiology and Parasitology in University "Ss Cyril and Methodius" Skopje.
$0.5 \%$, anaerobic flora appears, consisting of Bacteroides melaninogenicus, Treponema, Fusobacterium, Clostridium and Peptostreptococcus. Between 10-15\% of the population may contain yeasts, especially Candida and Geotrichum (3-5). However, the first species to colonise the enamel surface are the microorganisms from the Streptococcus viridans group, followed by Gram-positive anaerobic and microaerophylic bacilli, mostly from the Actinomycetes, Lactobacillus, and Bifidobacterium species. The majority of studies over the last few decades still emphasized Streptococcus mutans as a main pathogenic microorganism for dental caries occurrence (6-8). Lactobacilli constitute another group of important cariogenic microorganisms. Two species of lactobacilli, namely Lactobacillus casei and Lactobacillus rhamnosus, are regularly isolated from the oral cavity. Lactobacillus acidophilus is the most important species of this genus, and is commonly isolated from deep carious lesions $(1,4)$. A number of Actinomyces species have been isolated from the oral cavity. A relationship of Actinomyces odontolyticus with the very early stages of enamel caries has been reported. However, the most important human pathogen is Actinomyces israelii $(4,9)$.

Glass-ionomer cements (GIC) are considered anti-cariogenic, bearing in mind the fact that fluoride has antimicrobial properties (2). In order to improve the antimicrobial characteristics of both conventional and resin-modified glass ionomer cements (RMGIC), antimicrobial compounds have been added. In a number of studies the most frequently analyzed antimicrobial agent is chlorhexidine (14-18), although there are few data about incorporation of other antimicrobials. 
Cetylpirydinium Chloride $\left(\mathrm{C}_{21} \mathrm{H}_{38} \mathrm{NCl}\right)$ (CPC), as an active component of oral antiseptics has a broad antimicrobial spectrum, with strong bactericidal effect on Gram-positive pathogens and a fungicidal effect on fungi. Its effectiveness against Gram-negative pathogens and mycobacteria is questionable (10). In comparison to chlorhexidine, $\mathrm{CPC}$ has less residual effects, but as a result its effect against plaque and gingivitis is weaker. The combination of $\mathrm{CPC}$ with chlorhexidine and zinc lactate brings the highest reduction of both anaerobic and aerobic microorganisms, thus preventing the occurrence of bad breath (11). The effectiveness of CPC against oropharingeal candidiase has also been confirmed (12).

Benzalkonium Chloride (alkyldimethylbenzylammonium chloride) $(\mathrm{BC})$ is a strong biological agent with a moderate long effect. This compound is active against bacteria, some viruses, fungi and protozoa. Bacterial spores are considered to be resistant. Solutions are bacteriostatic and bactericidal depending on their concentration (4). Gram-positive bacteria are more sensitive than Gram-negative (13).

The improvement of the characteristics of the GICs resulting from the addition of antimicrobial agents, would solve the problems with the incomplete removal of the infective dentin, which would bring about future benefit for a better success of the atraumatic restorative treatment (ART) approach (19-28).

The present study has been undertaken to determine and compare the inhibition zones of conventional glass-ionomer cement following addition of $\mathrm{CPC}$ and $\mathrm{BC}$ on the cariogenic microorganisms (Streptococcus mutans, Lactobacillus casei and Actinomyces viscosus). The null hypothesis tested was that the incorporation of BC and CPC did not affect the antibacterial properties of the tested glass ionomer cement.

\section{Material and methods}

In this study, the following materials were used: (1) commercially available conventional glass-ionomer cement ChemFlex; (2) antimicrobial compounds: CPC produced by Sigma-Aldrich Co. under the trade-mark Cetylpyridinium Chloride C0732., and BC produced by Fluka Chemical Corporation Milwaukee, WI, USA, under the trade-mark Benzalkonium Chloride 12660.; (3) test strains of the following microrganisms: Streptococcus mutans - ATCC 25175, Lactobacillus casei - ATCC4646 and Actinomyces viscosus - ATCC19246 in lyophilized form, manufactured by American Type Culture Collection, Manassas, VA, USA; (4) bacterial growth media (a) BHIB - Brain Heart Infusion Broth, Oxoid, Wesel, Germany, ready to use media in $10 \mathrm{ml}$ test tubes; (b) Schaedler agar with addition of sheep blood - Oxoid, Wesel, Germany, ready to use growth media in Petri dishes with a diameter of $90 \mathrm{~mm}$; (5) anaerobic pots, with an atmosphere of $10 \%$ of carbon dioxide and $90 \%$ of nitrogen, employing an anaerobic system - Microbiology Anaerocult A, MERCK, Darmstadt, Germany.

\section{Preparation of the samples and incorporation of antimicrobial components}

Samples without incorporation of antimicrobials were prepared by mixing a certain amount of powder and liquid on mixing glass plates (according to the manufacturers' instructions). The freshly

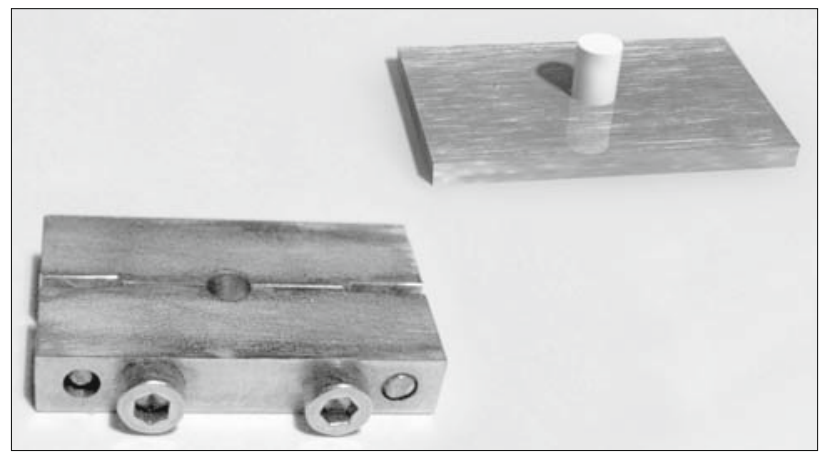

Fig. 1. Metal moulds. Special metal moulds for specimen preparation.

mixed paste was then put into metal moulds of dimensions: $6 \mathrm{~mm}$ (height) x $4 \mathrm{~mm}$ (diameter) (Fig. 1). The moulds were closed by metal plates on both sides, placed in special clamps, and incubated at $37^{\circ} \mathrm{C}$ for one hour (maturation time). Once removed from the incubator, the specimens were taken out from the clamps and moulds, and stored individually in separate marked plastic tubes with $5 \mathrm{ml}$ of deionised water at a temperature of $22-24{ }^{\circ} \mathrm{C}$ and at an air humidity of $40-50 \%$.

The antimicrobial compounds $\mathrm{CPC}$ and $\mathrm{BC}$ were first incorporated into the glass ionomer cement's polyacrylic acid by mixing, and then the powder has been added gradually, to the previously prepared acid and antimicrobial compound mixture, until complete saturation. The antimicrobial agents have been added in strict portions of 1,2 and $3 \%$ of the weight of the cement. The concentration (weight) of BC and CPC was measured with analytical balance (Mettler AE 200). Preceding analyses have determined the concentrations of 1,2 and $3 \%$ of antimicrobial agents to be equivalent to $0.0022 \mathrm{~g}, 0.0044 \mathrm{~g}$ and $0.0066 \mathrm{~g}$, of the whole cement mass. A total of 144 specimens were prepared, divided in two groups of 54 specimens each (six specimens of GIC ChemFlex incorporated with three different concentrations of antimicrobial agents - CPC and BC), and control group of 36 specimens without antimicrobial agents.

\section{Microbiological analysis}

The bacterial strains were inoculated into BHIB, and incubated in an anaerobic atmosphere at $37^{\circ} \mathrm{C}$ for $48 \mathrm{~h}$. From the bacteria grown in the liquid medium, the density of the inoculum was set to be equivalent to the McFarland 2 standard. Then, in previously marked Shaedler agar, $350 \mu \mathrm{L}$ of the bacterial suspension were equally spread using smear.

After inoculation, and additional period of 15 minutes necessary for the agar plate to absorb the bacterial suspension, sterile plastic tubes were used to make wells, $4 \mathrm{~mm}$ deep and $3.5 \mathrm{~mm}$ wide, into the agar plate. A total of 7 wells were prepared on each dish, 6 along the perimeter and one in the centre. The distance between the wells was $30 \mathrm{~mm}$, and the distance between the wells and the dish wall was $15 \mathrm{~mm}$. On each dish, three specimens having 1, 2 and $3 \%$ of $\mathrm{CPC}$, respectively, and another three samples having the corresponding percentages of $\mathrm{BC}$ were applied, along with one control sample (the glass-ionomer cement without antimicrobial compound). In this way, under equal conditions, different concen- 

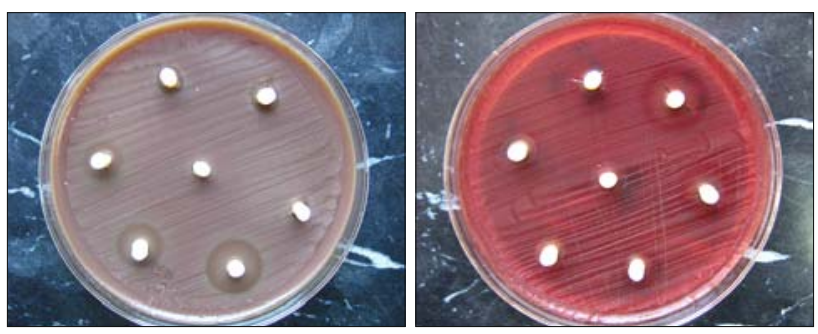

Figures 2 and 3. Zone of inhibition. Petri dishes with zone of inhibition formed around the specimens.

trations of each agent were mutually compared and the differences in the effects of the same concentrations of two different agents were compared as well. The specimens were carefully placed in the wells by sterile tweezers, so that they would have close contact with the agar, but would not tear it. The Petri dishes were left for 30 minutes at room temperature, and incubated anaerobically at $37^{\circ} \mathrm{C}$ for 48 hours. The first reading of the inhibitory effect (after the incubation period of 48 hours), was denoted as the effect at zero time.

The analysis of the delayed effect of antimicrobial agents were conducted after two, seven and 21 days. After each measurement the Petri dishes were transferred into thermostat on $37{ }^{\circ} \mathrm{C}$, and left until next measurements. 48 hours before every next measurements, the same specimens were continually transferred from thermostat onto fresh spread growth media and incubated in the same conditions (anaerobically at $37^{\circ} \mathrm{C}$ for 48 hours), until two, seven and 21 days, and the inhibition zones in this time intervals were read and marked (Figs 2 and 3).

By implementing this manner of continual preservation of the specimens, a simulation of the conditions in which the antimicrobial agents would have acted in vivo, i.e. in the human body (treated tooth) was provided.

The inhibition zone was determined by measuring its diameter, in millimeters. The size of the inhibition zone included the diameter of the specimen $(4 \mathrm{~mm})$. The measurements for each specimen were done in two perpendicular directions, and in cases when the width of the inhibition zone laid between two integers, it was measured to the nearest decimal point.

Statistical analysis was performed by One-way ANOVA followed by Post hoc-Tukey honest significant difference (HSD) test. The "Statistica" programme was used for data processing.

\section{Results}

The antimicrobial compound $\mathrm{BC}$ with the three analysed concentrations, incorporated in the ChemFlex glass-ionomer cement, establishes inhibition zones of different size against all tested bacteria (Tab. 1). On average, the inhibition zones are largest for the $3 \%$ of the antimicrobial compound at the first analysed (zero) time. Generally, there was a gradual decline in the inhibitory levels over time. Differences were statistically significant between the average values of the inhibition zones during the investigation

Tab. 1. Average inhibition zones of ChemFlex with Benzalkonium Chloride.

\begin{tabular}{|c|c|c|c|c|c|}
\hline Bacteria & Time & $\begin{array}{c}0 \%(\text { Control }) \\
\text { average }(\mathrm{mm}) \pm(\mathrm{SD})\end{array}$ & $\begin{array}{c}1 \% \\
\text { average }(\mathrm{mm}) \pm(\mathrm{SD})\end{array}$ & $\begin{array}{c}2 \% \\
\text { average }(\mathrm{mm}) \pm(\mathrm{SD})\end{array}$ & $\begin{array}{c}3 \% \\
\text { average }(\mathrm{mm}) \pm(\mathrm{SD})\end{array}$ \\
\hline \multirow[t]{4}{*}{ Streptococcus mutans } & $0 \mathrm{~h}$ & $4.58(0.49)$ & $11(0.9)$ & $13.33(0.82)$ & $14.92(0.81)$ \\
\hline & $48 \mathrm{~h}$ & $4.33(0.41)$ & $8(0.0)$ & $9.33(0.52)$ & $11.5(1.22)$ \\
\hline & $7 \mathrm{~d}$ & $4.58(0.38)$ & $5.17(0.41)$ & $6(1.1)$ & $7.17(1.17)$ \\
\hline & $21 \mathrm{~d}$ & $4.42(0.49)$ & $4.67(0.82)$ & $5.33(1.63)$ & $6.33(2.66)$ \\
\hline \multirow[t]{4}{*}{ Lactobacillus casei } & $0 \mathrm{~h}$ & $5.00(1.09)$ & $7.8(0.66)$ & $9.58(1.28)$ & $11.83(1.33)$ \\
\hline & $48 \mathrm{~h}$ & $4.58(0.49)$ & $5.92(0.49)$ & $7.25(0.61)$ & $8.83(0.98)$ \\
\hline & $7 \mathrm{~d}$ & $4.58(0.80)$ & $5.08(0.92)$ & $6.5(0.84)$ & $7.67(0.82)$ \\
\hline & $21 \mathrm{~d}$ & $4.83(0.93)$ & $4.5(0.55)$ & $6(0.63)$ & $7.5(0.55)$ \\
\hline \multirow[t]{4}{*}{ Actinomyces viscosus } & $0 \mathrm{~h}$ & $4.17(0.26)$ & $7.83(1.17)$ & $10.67(1.21)$ & $11.83(1.33)$ \\
\hline & $48 \mathrm{~h}$ & $4.75(0.76)$ & $6.58(1.28)$ & $8.75(2.36)$ & $10.67(3.83)$ \\
\hline & $7 \mathrm{~d}$ & $4.83(0.75)$ & $5.33(0.82)$ & $6.83(1.17)$ & $8.5(2.07)$ \\
\hline & $21 \mathrm{~d}$ & $4.00(0.00)$ & $5.83(2.04)$ & $7.33(2.66)$ & $9.33(3.01)$ \\
\hline
\end{tabular}

Tab. 2. Average inhibition zones of ChemFlex with Cetylpyridinium Chloride.

\begin{tabular}{|c|c|c|c|c|c|}
\hline Bacteria & Time & $\begin{array}{c}0 \%(\text { Control }) \\
\text { average }(\mathrm{mm}) \pm(\mathrm{SD})\end{array}$ & $\begin{array}{c}1 \% \\
\text { average }(\mathrm{mm}) \pm(\mathrm{SD})\end{array}$ & $\begin{array}{c}2 \% \\
\text { average }(\mathrm{mm}) \pm(\mathrm{SD})\end{array}$ & $\begin{array}{c}3 \% \\
\text { average }(\mathrm{mm}) \pm(\mathrm{SD})\end{array}$ \\
\hline \multirow[t]{4}{*}{ Streptococcus mutans } & $0 \mathrm{~h}$ & $4.58(0.49)$ & $6.08(0.92)$ & $7.58(1.02)$ & $8.5(0.77)$ \\
\hline & $48 \mathrm{~h}$ & $4.67(0.82)$ & $4.92(0.80)$ & $6.5(0.89)$ & $7.42(0.80)$ \\
\hline & $7 \mathrm{~d}$ & $4.50(0.45)$ & $4(0.0)$ & $5(0.89)$ & $7.17(1.60)$ \\
\hline & $21 \mathrm{~d}$ & $4.50(0.45)$ & $4(0.0)$ & $4.67(0.82)$ & $6.5(0.84)$ \\
\hline \multirow[t]{4}{*}{ Lactobacillus casei } & $0 \mathrm{~h}$ & $5(1.09)$ & $4.25(2.21)$ & $5.92(0.80)$ & $6.67(0.26)$ \\
\hline & $48 \mathrm{~h}$ & $4.42(0.49)$ & $4.08(0.20)$ & $4.5(0.63)$ & $6(0.0)$ \\
\hline & $7 \mathrm{~d}$ & $5(0.55)$ & $4(0.0)$ & $4(0.0)$ & $5.83(0.75)$ \\
\hline & $21 \mathrm{~d}$ & $5(0.89)$ & $4(0.0)$ & $4(0.0)$ & $5.33(0.52)$ \\
\hline \multirow[t]{4}{*}{ Actinomyces viscosus } & $0 \mathrm{~h}$ & $4.17(0.26)$ & $6,42(1,20)$ & $8,08(1,36)$ & $9,0(1,30)$ \\
\hline & $48 \mathrm{~h}$ & $4.5(0.45)$ & $6,75(1,33)$ & $8,58(2,25)$ & $10,25(3,37)$ \\
\hline & $7 \mathrm{~d}$ & $5.17(0.68)$ & $5,08(0,80)$ & $6,08(0,80)$ & $7,33(1,03)$ \\
\hline & $21 \mathrm{~d}$ & $4.5(0.84)$ & $4,33(0,8)$ & $5,17(0,98)$ & $6,16(0,98)$ \\
\hline
\end{tabular}


Tab. 3. Statistical significance ( $p>0.05$ ) obtained by One-way ANOVA followed by the Post-hoc-Tukey honest significant difference (HSD) test.

\begin{tabular}{lccc}
\hline P-value & time & $\begin{array}{c}\text { ChemFlex with } \\
\text { Benzalkonium } \\
\text { Chloride }\end{array}$ & $\begin{array}{c}\text { ChemFlex with } \\
\text { Cetylpyridinium } \\
\text { chloride }\end{array}$ \\
\hline Streptococcus mutans & $0 \mathrm{~h}$ & 0.000000 & 0.000000 \\
& $48 \mathrm{~h}$ & 0.000000 & 0.000024 \\
& $7 \mathrm{~d}$ & 0.000234 & 0.000059 \\
& $21 \mathrm{~d}$ & $0.208924^{*}$ & 0.000006 \\
\hline Lactobacillus casei & $0 \mathrm{~h}$ & 0.000000 & 0.023282 \\
& $48 \mathrm{~h}$ & 0.000000 & 0.000000 \\
& $7 \mathrm{~d}$ & 0.000013 & 0.000002 \\
& $21 \mathrm{~d}$ & 0.000001 & 0.000216 \\
\hline Actinomyces viscosus & $0 \mathrm{~h}$ & 0.000000 & 0.000002 \\
& $48 \mathrm{~h}$ & 0.002001 & 0.001096 \\
& $7 \mathrm{~d}$ & 0.000418 & 0.000455 \\
& $21 \mathrm{~d}$ & 0.004191 & 0.009255 \\
\hline
\end{tabular}

and between the percentual values, except at day 21 for Streptococcus mutans (Tab. 3).

After incorporation of CPC in the ChemFlex GIC, there is also establishment of inhibition zones with different values. In this case the largest inhibition zones are noted for the $3 \%$ of the compound, with a drop in the average inhibition zones with time. The largest zone of inhibition was observed after 48 hours against the Actinomyces viscosus, which is at the same time the largest zone obtained (Tab. 2). According to the statistical analysis, there are statistically significant differences between the average values of the inhibition zones during all investigated periods (Tab. 3).

The glass-ionomer cement without antimicrobial compound shows certain small inhibition zones, which vary from $4.17 \mathrm{~mm}$ to $6 \mathrm{~mm}$ (Tabs 1 and 2).

\section{Discussion}

The comparative analysis of the results provides us with an answer to the question which concentration of antimicrobial compound incorporated in the glass-ionomer cement has a better effect on the analysed microorganisms. With respect to the effect of the compounds incorporated with $1 \%, 2 \%$ and $3 \%$ on the Streptococcus mutans, $\mathrm{BC}$ gives the largest average inhibition zones. Considering Lactobacillus casei, the largest inhibition zones both for $1 \%$ and $2 \%$ of the antimicrobial compounds are obtained by the combination of ChemFlex with $\mathrm{BC}$, and the smallest inhibition zones, i.e. the weakest effect against the analysed bacteria is exhibited by the combination of the ChemFlex with the addition of CPC. The data from the analysis of the effect of the antimicrobial glass-ionomer cements against Actinomyces viscosus bacteria correspond to those against Streptococcus mutans.

The largest number of studies analyse the antimicrobial effect of the chlorhexidine compound in the form of diacetate, gluconate, digluconat, hydrochloride or dihydrochloride, incorporated in conventional and modified glass-ionomer cements, most often in the powder of the glass-ionomer cements $(14,16,17,18,29$, $31)$. The antimicrobial effect against the cariogenic microorganisms Streptococcus mutans, Lactobacillus casei and Actinomyces viscosus is most often analysed $(16,18,29,31)$. The most often exploited microbiological method is the agar-diffusion test $(14,16$, $18,29-31$ ), and the inhibition zones are determined in millimetres, except for the study by Botelho (29), where the results express the cumulative effect of the compounds, given in areas of inhibition $\left(\mathrm{mm}^{2}\right)$. The shape and the way of placement of the cements on the Petri dishes is an issue. Globally, there are two ways of placement - preparation of wells of certain dimensions in the agar and placement of the freshly mixed cement (the so called unset cement), preparation of samples of the cement, its setting and maturation in laboratory conditions, and placement of the samples in the previously prepared wells in the agar (set cement), as was done in this study. The opinion as to which way of analysis of the antimicrobial properties is better, differ. Of course, the opinion that the unset cements produce higher inhibition zones has been confirmed (16, 30 ), which is logical because of the still high mobility of the molecules of the compounds in the liquid consistency. In any case, if the antimicrobial effect of unset materials is to be determined, an analysis should also be carried out with samples prepared from the same materials under the same working conditions. Regarding the inhibition zones, the majority of studies speak about the forming of higher zones with an increase of the concentration, but of a decline of the zones with time (16, 29-31). However, there are also some opposite opinions, i.e. that the inhibition zones are not dependant on the concentrations or the kind of the incorporated compound (18). The time of incubation of the Petri dishes varies, too. In some studies it is 24 hours (16), and in most of them it is 48 hours $(18,29-31)$, which is in principle a better solution for the higher growth of the inoculated bacteria. The sizes of the samples of the set cement vary with most authors, which has to have an influence on the size of the inhibition zones. In his study Botelho (29), among other issues, analysed also the effects of the antimicrobial compounds CPC and BC incorporated in the Fuji IX GIC against the same microorganisms which were investigated in this study. In the current study, generally BC has given the largest inhibition zones, even compared to chlorhexidine (which is in accordance with our results). CPC produces smaller zones for all combinations and against all bacteria. Takahashi (18) performed analyses of Fuji IX GIC to which different concentrations and combinations of CHX have been added, against the Streptococcus mutans, Lactobacillus casei and Actinomyces viscosus. For all combinations, the inhibition zones against Streptococcus mutans and Lactobacillus casei do not show any statistically significant differences. According to the majority of reference data $(18,29-$ 31 ), the restorative materials, and first of all the glass-ionomer cements in which no antimicrobial compounds or elements have been incorporated, do not form any inhibition zones. In his study Vermeersch (31) analyses the antimicrobial effect of a number of restorative materials without any addition of antimicrobial compounds: the conventional GIC - Ketac Fil Plus, the resin-modified GIC - Fuji II Liner, the resin-modified liner Vitrebond, the compomer Dyract and the antibiotic ampiciline as a control. The results of the study showed that when we exclude the antibiotic, the largest inhibition zones occurred for the resin-modified GIC - Fuji II Liner, the resin-modified liner Vitrebond, but also that most materials did not form any inhibition zones. 


\section{Conclusions}

Following the increase in the concentration of the antimicrobial compounds, the average inhibition zones against the three analysed microorganisms also increased. The glass-ionomer cement without incorporation of antimicrobial compounds either forms very small or non-existent inhibition zones.

Based on the effect of the antimicrobial compounds against the investigated bacteria we can conclude that the combination ChemFlex with Benzalkonium Chloride has the best effect on Streptococcus mutans and Actinomyces viscosus as well as on the Lactobacillus casei. The weakest effect against this bacterium is the effect of the combination ChemFlex with CPC. The Benzalkonium Chloride antibacterial compound has a stronger antibacterial effect than Cetylpyridinium Chloride.

\section{References}

1. Bratthall D, Tynelius GB. Diagnostics as basis of causal treatment: Tools and tests for evaluation of caries and periodontal diseases. In: Anderson MH, Bratthall D, Einwag J, Elderton RJ, Ernst CP, Levin RP, Tynelius-Bratthall G, Willershausen-Zönnchen B (Eds). Proffesional Prevention in Dentistry. Baltimore-Philadelphia-Hong Kong-London-Munich-Sydney-Tokyo: A Waverly Company; 1994, 47-56, 101-120.

2. Wilson AD, Groffman DM, Kuhn AT. The release of fluoride and other chemical species from a glass ionomer cement. Biomaterials 1985; 6 (6): 431-433.

3. Edgar WM, O’Mullane DM, editors. Saliva and Oral Health. British Dental Association; 1999.

4. Samaranayake LP(Ed). Essential Microbiology for Dentistry. Churchill Livingstone; 1996, 73-84, 89-90, 267-310.

5. Brooks GF, Carroll CK. Bacteriology. In: Weitz M, Lebovitz H (Eds). Yawetz, Melnick \& Adelberg's Madical Microbiology. New York: McGrawHill; 2010, 145-209.

6. Campus G, Lumbau A, Bachisio SL. Caries experience and streptococci and lactobacilli salivary levels in 6-8-year-old Sardinians. Int J Pediatr Dent 2000; 10 (4): 306-312.

7. Llena-Pay MC, Montanana-Llorens C, Forner-Navarro L. Cariogenic oral flora and its relation to dental caries. J Dent Child 2000; 67 (1): 42-46.

8. Thibodeau EA, O'Sullivan DM. Salivary mutans streptococci and caries development in the primary and mixed dentitions of children. Community Dent Oral Epidemiol 1999; 27 (6): 406-412.

9. Shen S, Samaranayake LP, Yip HK. Coaggregation profiles of the microflora from root surface caries lesions. Arch Oral Biol 2005; 50 (1): 23-32.

10. Radford JR, Beighton D, Nugent Z, Jackson RJ. Effect of use of $0.05 \%$ cetylpyridinium chloride mouthwash on normal oral flora. J Dent 1997; 25 (1): 35-40.

11. Van Steenberghe D, Avontroodt P, Peeters W, Pauwels M, Coucke W, Lijnen A, Quirynen M. Effect of different mouthrinses on morning breath. J Periodontol 2001; 72 (9): 1183-1191.

12. Pitten FA, Kramer A. Efficacy of cetylpyridinium chloride used as oropharingeal antiseptic. Arzneimittelforschung 2001; 51 (7): 588-595.

13. Merianos JJ. Quaternary ammonium antimicrobial compounds. In: Block SS, editor. Disinfection, Sterilization and Preservation. 4th ed. Philadelphia-London: Lea Febiger; 1991, 225-255.
14. Jedrychowski JR, Caputo AA, Kerper S. Antibacterial and mechanical properties of restorative materials combined with chlorhexidines. J Oral Rehabil 1983; 10 (5): 373-381.

15. Palmer G, Jones FH, Billington RW, Pearson GJ. Chlorhexidine release from an experimental glass ionomer cement. Biomaterials 2004; 25 (23): 5423-5431.

16. Ribeiro J, Ericson D. In vitro antibacterial effect of chlorhexidine added to glass-ionomer cements. Scand J Dent Res 1991; 99 (6): 533-540.

17. Sanders BJ, Gregory RL, Moore K, Avery DR. Antibacterial and physical properties of resin modified glass-ionomers combined with chlorhexidine. J Oral Rehab 2002; 29 (6): 553-558.

18. Takahashi Y, Imazato S, Kaneshiro AV, Ebisu S, Frencken JE, Tay FR. Antibacterial effects and physical properties of glass-ionomer cements containing chlorhexidine for the ART approach. Dent Mater 2006; 22 (7): 647-652.

19. Frencken J, Pilot T, Songpaisan $Y$, Phantumvanit P. Atraumatic Restorative Treatment (ART): rationale, technique and development. J Public Health Dent. 1996; 56 (3): 135-140.

20. Bresciani E. Clinical trials with atraumatic restorative treatment (ART) in deciduos and permanent teeth. J App Oral Sci 2006; 14 Suppl: 14-19.

21. Davidovich E, Weiss E, Fuks AB, Beyth N. Surface antibacterial properties of glass ionomer cements used in atraumatic restorative treatment. J Am Dent Assoc 2007; 138 (10): 1347-1352.

22. El-Nadeef M, Saleh A, Amin S, Honkala E. Assessment of the atraumatic restorative treatment for the schoolchildren in Egypt. J Minim Interv Dent 2009; 2 (3): 170-177.

23. Yip HK, Smales RJ. Glass ionomer cements used as fissure sealants with the atraumatic restavrative treatment (ART) approach: review of literature. Int Dent J 2002; 52 (2): 67-70.

24. Lopez N, Simpser-Rafalin S, Berthold P. Atraumatic restorative treatment for prevention and treatment of caries in an underserved community. Am J Public Health 2005; 95 (8): 1338-1339.

25. Mickenautsch S, Grossman ES. Atraumatic restorative treatment (ART) - factors affecting success. J Appl Oral Sci 2006; 14 (Suppl): 34-36.

26. Momesso MGC, da Silva RC, Imparato JCP, Molina C, Navarro RS, Ribeiro SJL. "In Vitro" surface roughness of different glass ionomer cements indicated for ART restorations. Braz J Oral Sci 2010; 9 (2): 77-80.

27. Roshan NM, Shigli AL, Desphande SD. Microbiological evaluation of salivary Streptococcus mutans from children of age 5-7 years, pre- and postatraumatic restorative treatment. Contemp Clin Dent 2010; 1 (2): 94-97.

28. Schriks MCM, van Amerongen WE. Atraumatic perspective of ART: psychological aspects of treatment with and without rotary instruments. Community Dent Oral Epidemiol 2003; 31 (1): 15-20.

29. Botelho MG. Inhibitory effects on selected oral bacteria of antibacterial agents incorporated in a glass ionomer cements. Caries Res 2002; 37 (2): 108-114.

30. Turkun SL, Turkun M, Ertugrul F, Ates M, Brugger S. Long-term antibacterial effects and physical properties of a chlorhexidine - cintaining glass ionomer cements. J Esthet Restor Dent 2008; 20 (1): 29-44.

31. Vermeersch G, Leloup G, Delmee M, Vreven J. Antibacterial activity of glass-ionomer cements, compomers and resin composites: relationship between acidity and material setting phase. J Oral Rehab 2005; 32 (5): 368-374.

Received April 16, 2015. Accepted August 18, 2015. 